\title{
Targeting the hypoxia-inducible factor (HIF) pathway in cancer
}

\section{Evon Poon ${ }^{1}$, Adrian L. Harris ${ }^{2}$ and Margaret Ashcroft ${ }^{1, \star}$}

The central component of hypoxia sensing in the cell is the hypoxia-inducible factor (HIF) transcriptional complex. HIF activity is deregulated in many human cancers, especially those that are highly hypoxic. Hypoxic tumour cells are usually resistant to radiotherapy and most conventional chemotherapeutic agents, rendering them highly aggressive and metastatic. Overexpression of HIF- $\alpha$, the regulatory subunit of HIF, is associated with increased vascular density, severity of tumour grade, treatment failure and a poor prognostic outcome with conventional therapies. Therefore HIF is an attractive, although challenging, therapeutic target, and several different strategies have been developed to target HIF directly or indirectly in recent years. This review outlines the preclinical and clinical advances in this arena and discusses which cancers may benefit from HIF-targeted therapy.

Hypoxia is a common characteristic of all solid tumours (Ref. 1) and is a condition in which proliferating tumour cells are deprived of oxygen due to a limited blood supply from abnormal tumour microvasculature (Fig. 1). Hypoxic cells are at risk of stress-induced insults including oxidative DNA damage, DNA strand breaks and genetic aberrations, which can restrain growth and ultimately result in cell death. However, cancer cells show a range of genetic changes that improve survival and enable them to adapt to hypoxic conditions. As a result, hypoxic tumour cells continue to proliferate, are associated with a more invasive and metastatic phenotype and are usually resistant to conventional treatments such as radiotherapy and chemotherapy (Refs 2, 3, 4, 5, 6). Therefore, gaining a clearer understanding of the underlying molecular mechanisms involved in hypoxia signalling in cancer cells and how these processes might become deregulated in different cancer types is likely to result in better targeting of hypoxic tumour cells and more-effective treatments for solid tumours. A central component of hypoxia signalling in the cell is hypoxia-inducible factor (HIF), which is critically involved in both sensing and responding to changes in cellular oxygen (Ref. 7). This review outlines the therapeutic strategies used to target HIF/ hypoxic signalling in tumour cells and discusses recent advances made in this area.

${ }^{1}$ Centre for Cell Signalling and Molecular Genetics, University College London, Division of Medicine, London, UK.

${ }^{2}$ Cancer Research UK Department of Medical Oncology, The Weatherall Institute of Molecular Medicine, University of Oxford, John Radcliffe Hospital, Oxford, UK.

${ }^{*}$ Corresponding author: Margaret Ashcroft, Centre for Cell Signalling and Molecular Genetics, University College London, Division of Medicine, Rayne Building, 5 University Street, London, WC1E 6JJ, UK. Tel: +44 (0)20 7679 6205; Fax: +44 (0)20 7679 6211; E-mail: m.ashcroft@ucl.ac.uk 

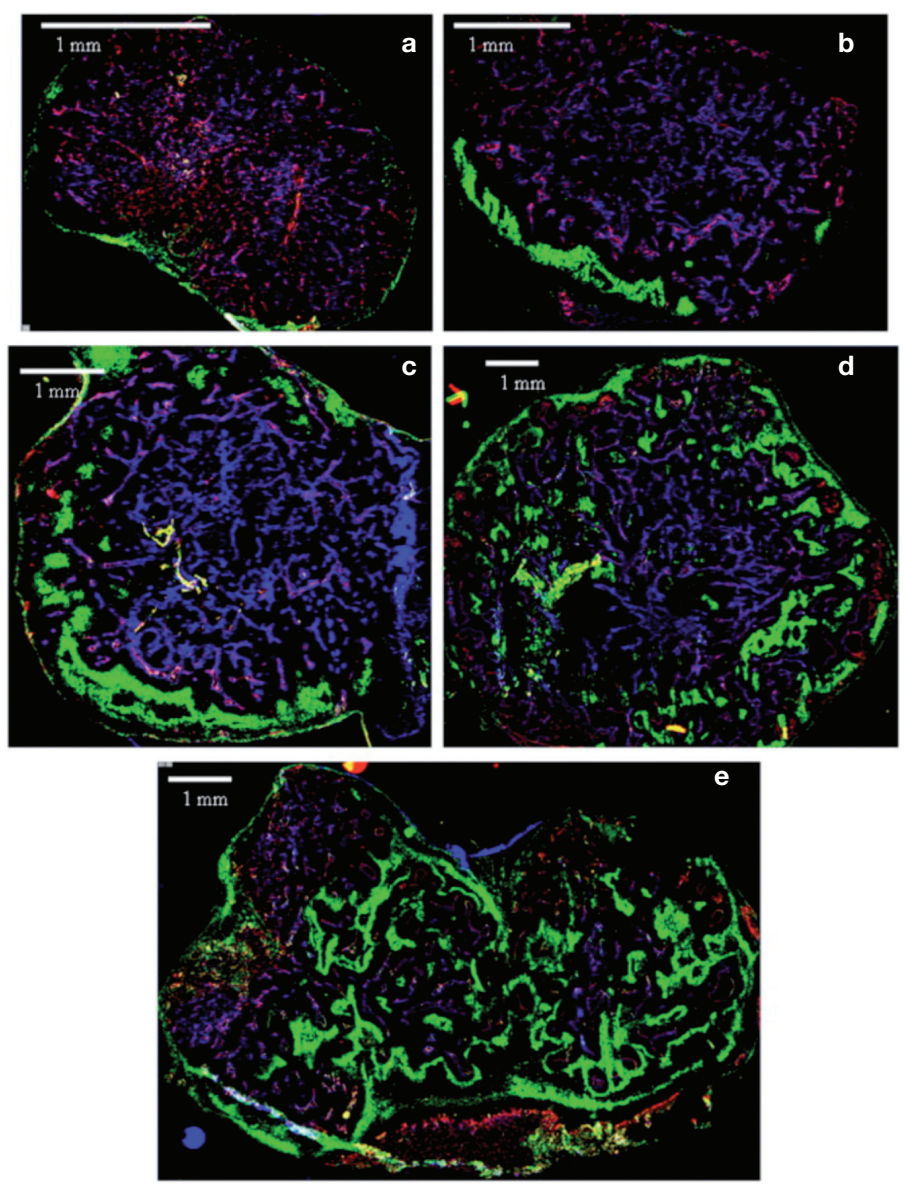

\section{Increased hypoxia is detected at increasing tumour size}

Expert Reviews in Molecular Medicine 2009 Published by Cambridge University Press

Figure 1. Increased hypoxia is detected at increasing tumour size. The figure shows fluorescence imaging of human glioblastoma xenograft tumours. Tumours from the human glioblastoma multiforme tumour cell line E106 were transplanted subcutaneously into nude mice. Tumours were harvested when they reached a mean size of $2 \mathrm{~mm}$ (a), $4 \mathrm{~mm}$ (b), $6 \mathrm{~mm}$ (c), $8 \mathrm{~mm}$ (d) and $10 \mathrm{~mm}$ (e). Tumour sections were stained with antipimonidazole (green) to indicate areas of hypoxia, 9F1 (a monoclonal antibody to mouse endothelium; red) to assess vasculature, and Hoechst 33324 (blue) for nuclei. As tumour size increased, the vascular architecture became less organised. This figure was kindly provided by Dr Jan Bussink (Department of Radiation Oncology 874, Radboud University Nijmegen, The Netherlands) and is reprinted from Ref. 153, with permission from Elsevier (C) 2009 Elsevier).

\section{The HIF pathway}

HIF is a transcriptional complex activated in response to changes in cellular oxygen levels and mediates the expression of many genes (Refs 8, 9). HIF target genes encode proteins that are involved in the regulation of various aspects of tumour biology, including oxygen transport, iron metabolism, glycolysis, glucose transport, cell survival and proliferation, angiogenesis, invasion and metastasis. HIF activity is deregulated in many human cancers, and this is most commonly due to the overexpression of HIF- $\alpha$, the regulatory subunit of the HIF complex. Overexpression of HIF- $\alpha$ is usually associated with increased vascular density, severity of tumour grade, treatment failure and a poor prognostic outcome (Refs 10, 11). Blocking HIF activity or targeting HIF- $1 \alpha$ expression in tumours has been shown to significantly slow tumour growth in xenograft 
models (Ref. 12) and render hypoxic cells more susceptible to killing by conventional therapies (Refs 13, 14, 15, 16).

\section{HIF-1: structure and regulation}

The HIFs belong to a family of structurally related basic-helix-loop-helix (bHLH)-containing proteins (Ref. 7). The prototype of the family is HIF-1. HIF-1 consists of two subunits: the regulatory HIF- $1 \alpha$ subunit and the ubiquitously expressed HIF-1 $\beta$ subunit (also known as aryl hydrocarbon receptor nuclear translocator, ARNT). HIF- $1 \alpha$ protein is composed of four functional domains: a bHLH domain and a PER-ARNTSIM (PAS) domain (involved in dimerisation and DNA binding), an oxygen-dependent degradation (ODD) domain (required for targeting to the proteasome and degradation), and two transactivation domains (N-TAD and C-TAD) required for transcriptional activation (Ref. 17) (Fig. 2). HIF-1 $\beta$ contains bHLH, PAS and transactivation domains (Ref. 18).

Whereas HIF-1 $\beta$ is constitutively expressed in cells, the availability of HIF- $1 \alpha$ is dependent on cellular oxygen levels. In normoxia (21\% oxygen levels), HIF- $1 \alpha$ protein is rapidly and continuously expressed and degraded (for review, see Ref. 9). The synthesis of HIF-1 $\alpha$ protein is regulated by oxygen-independent mechanisms involving growth-factor-mediated activation of the phosphoinositide 3-kinase (PI3K) and mitogen-activated protein kinase (MAPK) pathways (Refs 19, 20). HIF-1 $\alpha$ protein degradation is controlled by the ODD domain, and deletion of the entire ODD region renders HIF- $1 \alpha$ stable even in the absence of hypoxia signalling (Ref. 21). Hydroxylation of proline residues 402 and 564 within the ODD domain of HIF- $1 \alpha$ mediates its interaction with the von Hippel-Lindau tumour suppressor protein (pVHL), which is the recognition component of an E3 ubiquitin ligase, leading to HIF-1 $\alpha$ ubiquitination and subsequent degradation by the 26S proteasome (Refs 22, 23, 24, 25). The hydroxylation process is governed by three evolutionarily conserved HIF prolyl hydroxylases - PHD1 (EGLN2), PHD2 (EGLN1) and PHD3 (EGLN3) - and their activity depends on the availability of oxygen, iron, 2-oxoglutarate and ascorbate (Refs 26, 27). Interestingly, it has been shown by using small interfering RNA (siRNA) techniques that PHD2 plays a predominant role in controlling HIF- $1 \alpha$ levels (Ref. 28).

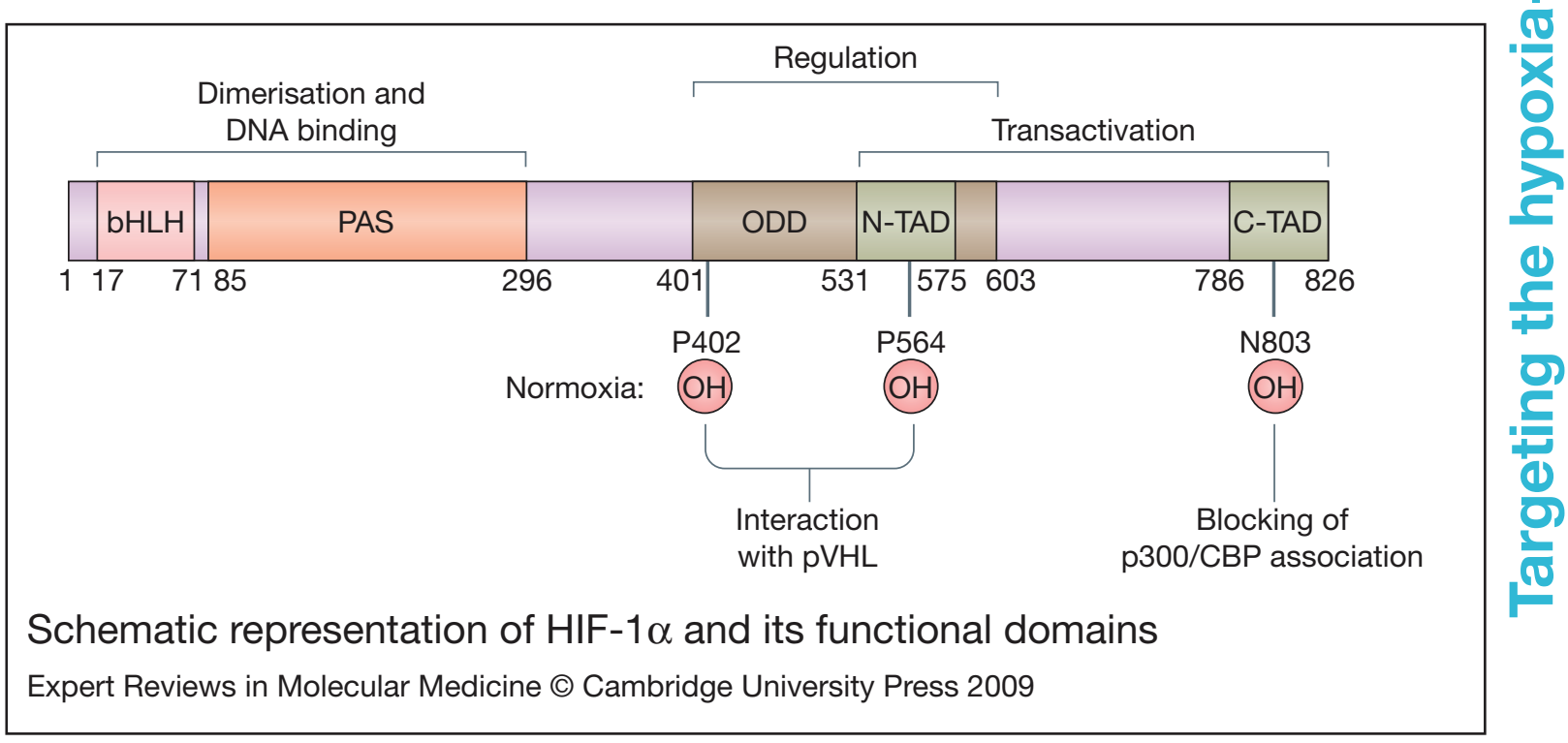

Figure 2. Schematic representation of HIF-1 $\alpha$ and its four functional domains. The basic-helix-loop-helix $(\mathrm{bHLH})$ and PER-ARNT-SIM (PAS) domains of hypoxia-inducible factor $1 \alpha(\mathrm{HIF}-1 \alpha)$ are involved in dimerisation and DNA binding; the oxygen-dependent degradation (ODD) domain is required for degradation via the proteasome; and the transactivation domains (N-TAD and C-TAD) are involved in transactivation activity. Hydroxylation of proline residues 402 and 564 within the ODD domain mediates its interaction with the von Hippel-Lindau tumour suppressor protein (pVHL). Hydroxylation of asparagine 803 in the C-TAD blocks its association with transcriptional coactivator p300/CBP.

Accession information: doi:10.1017/S1462399409001173; Vol. 11; e26; August 2009 (C) Cambridge University Press 2009 
Under hypoxic conditions, prolyl hydroxylation within the ODD domain is inhibited and the interaction of HIF- $1 \alpha$ with pVHL is prevented. As a result, HIF- $1 \alpha$ ubiquitination and degradation is blocked and consequently the level of the protein increases. The accumulated HIF- $1 \alpha$ translocates to the nucleus where it dimerises with HIF-1 $\beta$ (Ref. 7) via the bHLH and part of the PAS domain to form the HIF-1 complex. HIF-1 recruits transcriptional coactivators such as p300/CBP (p300/CREBbinding protein) (Ref. 29) and binds to the hypoxia-response element (HRE) within the promoter region of HIF-1-responsive target genes (Ref. 30), thereby mediating their transcriptional activation.

The transcriptional activity of HIF-1 is also controlled by an asparagine hydroxylase known as FIH-1 (factor inhibiting HIF-1) (Refs 31, 32, 33, 34, 35). In normoxia, hydroxylation of Asn803 in the C-TAD of HIF- $1 \alpha$ blocks its association with p300/CBP. FIH-1 was also reported to interact with pVHL to modulate HIF-1 $\alpha$ protein stabilisation (Ref. 35). Thus, FIH- 1 acts as a negative regulator of HIF- $1 \alpha$ to suppress transcriptional activity.

\section{Other HIF- $\alpha$ family members}

Two other HIF- $\alpha$ isoforms have been identified: HIF- $2 \alpha$ and HIF-3 $\alpha$ (Ref. 36). HIF-2 $\alpha$ has a similar structure to HIF-1 $\alpha$ (Ref. 37). Like HIF$1 \alpha$, HIF- $2 \alpha$ is rapidly induced in response to hypoxia, negatively regulated by the pVHL ubiquitin E3 ligase complex, and can mediate the transcriptional activation of a number of known HIF-1 target genes (Ref. 38). However, the expression of HIF- $2 \alpha$ is cell-type specific and it has a distinct biological role from HIF- $1 \alpha$ (Refs 39, 40, 41, 42, 43), with particular importance in renal cancer and vascular biology. In development, HIF- $1 \alpha$ and HIF- $2 \alpha$ were demonstrated to have nonoverlapping functions: HIF- $1 \alpha^{-/-}$and HIF- $2 \alpha^{-/-}$mouse embryos have different phenotypes and developmental defects (Ref. 40). HIF-2 $\alpha$ is also expressed at a higher level than HIF-1 $\alpha$ in several pVHL-defective renal carcinoma cell lines (Refs 42, 44), and various groups have reported that HIF-1 and HIF-2 can regulate both overlapping and distinct target genes (Refs 39, 41, 43).

The function of HIF-3 $\alpha$ is not well understood. Several splice variants of HIF-3 $\alpha$ have been identified (Ref. 45). One of the HIF-3 $\alpha$ splice variants, known as the inhibitory PAS domain protein (IPAS), can function as a dominant negative regulator of hypoxia-inducible gene expression: it binds to the HIF- $1 \alpha$ subunit to form a nonfunctional complex in the nucleus, impairing the expression of HIF-1 target genes under hypoxic conditions (Ref. 46). Interestingly, it has been reported recently that IPAS gene expression is induced in response to hypoxia and is regulated directly by HIF-1 binding, forming a further level of negative feedback in the hypoxia-response system (Ref. 47).

\section{HIF and cancer}

In addition to hypoxia, loss-of-function mutations in several genes involved in the oxygen-sensing mechanism have also been shown to contribute to the overexpression of HIF- $\alpha$ (HIF- $1 \alpha$ and HIF- $2 \alpha$ ) and activation of the HIF pathway in tumour cells (Fig. 3). For example, loss-offunction mutations in VHL have been shown to increase HIF- $1 \alpha$ and HIF- $2 \alpha$ expression in clearcell renal carcinoma, haemangioblastoma and other VHL-associated tumours due to the lack of HIF- $\alpha$ ubiquitination and degradation (Ref. 44). Mutations in succinate dehydrogenase (SDH) and fumarate hydratase (FH) inhibit prolyl hydroxylase activity, resulting in abnormal stabilisation of HIF- $1 \alpha$ and upregulation of HIF target genes such as vascular endothelial growth factor (VEGF) in several cancers, namely paragangliomas, phaeochromocytomas, leiomyomas and renal cell cancers (Refs 48, 49).

Dysregulation of key signal transduction pathways also contributes to the overexpression of HIF- $1 \alpha$ and activation of HIF-1 in cancer. Tumour cells with constitutive activation of the Ras-MAPK pathway (Ref. 50), Src (Ref. 51) or the PI3K-AKT(PKB)-mTOR (mammalian target of rapamycin) pathway (Refs 52, 53) have elevated expression of HIF-1 $\alpha$ protein. Loss of function of tumour suppressor proteins such as PTEN (which leads to constitutive activation of AKT) (Refs 54, 55) and p53 can also result in increased HIF-1 activity (Fig. 3).

Since HIF- $\alpha$ (HIF- $1 \alpha$ and HIF- $2 \alpha$ ) is induced in cancer cells in response to hypoxia and growth factors, and as a result of known genetic abnormalties, it is no surprise then that HIF- $\alpha$ protein has been shown to be overexpressed in human tumour biopsy samples. Immunohistochemical analyses of paraffinembedded tissue sections have shown HIF-1 $\alpha$ 


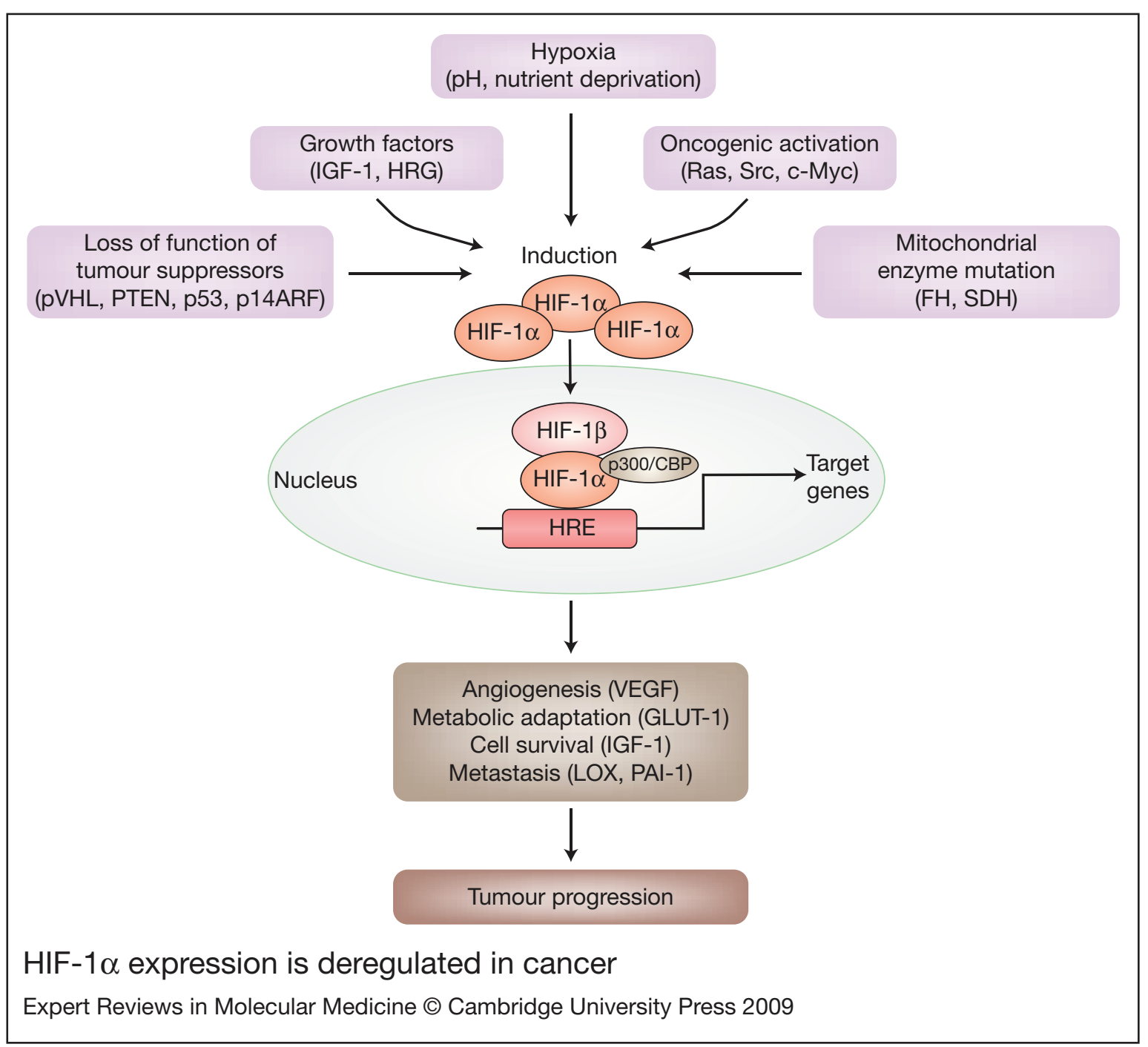

Figure 3. HIF-1 $\alpha$ expression is deregulated in cancer. Overexpression of hypoxia-inducible factor $1 \alpha(\mathrm{HIF}-1 \alpha)$ and activation of the HIF pathway in cancer is caused by a combination of microenvironmental changes, such as changes in oxygen levels (hypoxia), $\mathrm{pH}$ and nutrients (deprivation), increases in growth factors, and genetic abnormalities leading to loss of tumour suppressor function, oncogenic activation or deregulated mitochondrial function. Increased HIF- $\alpha$ protein in cancer cells translocates to the nucleus, binds to HIF-1 $\beta$, recruits coactivators (e.g. p300/CBP) and activates the transcription of multiple genes involved in angiogenesis (e.g. VEGF), metabolic adaptation (e.g. GLUT-1), cell survival (e.g. IGF-1) and metastasis (e.g. LOX, PAI-1) - thereby driving tumour progression. Abbreviations: FH, fumarate hydratase; GLUT-1, glucose transporter 1; HRG, heregulin; IGF-1, insulin-like growth factor 1; LOX, lysyl oxidase; p300/CBP, p300/ CREB-binding protein; p14ARF, alternate reading frame (ARF) product of CDKN2A (cyclin-dependent kinase inhibitor 2A) locus; PAl-1, plasminogen activator inhibitor 1; PTEN, phosphatase and tensin homologue; pVHL, von Hippel-Lindau tumour suppressor protein; SDH, succinate dehydrogenase; VEGF, vascular endothelial growth factor.

(nuclear) to be highly expressed in many tumour types including pancreatic (Ref. 56), head and neck (Refs 57, 58), oropharyngeal (Ref. 59), breast (Refs 60, 61), renal (Ref. 62), ovarian (Ref. 63), urothelial (Ref. 64), bladder, brain, colorectal and prostate (Ref. 65). Several independent studies have revealed a strong correlation between HIF- $1 \alpha$ overexpression and patient mortality. High HIF- $1 \alpha$ expression has also been associated with low survival rates in pancreatic carcinoma (Ref. 56), head and neck squamous cell carcinoma (Ref. 58), clear-cell 
renal cell carcinoma (Ref. 62) and breast carcinoma (Refs 60, 61). This might be because the overexpression of HIF- $1 \alpha$, which often indicates significant levels of tumour hypoxia, is involved in mediating cellular adaptive responses that enable tumour cells to survive. Tumour hypoxia and HIF-1 $\alpha$ overexpression is reported to correlate with an increased aggressiveness of tumour cell behaviour, angiogenesis (Ref. 57) and metastasis (Ref. 61) and can be used as a marker to predict outcome in patients with metastatic disease. Interestingly, a study in clear-cell renal cell carcinoma has shown that HIF- $1 \alpha$ expression directly correlates with markers of apoptosis (p53) and growth inhibition (p21), the mTOR pathway (AKT, p27), the chemokine receptors CXCR3 and CXCR4, and proteins of the VEGF family (Ref. 62). Therefore, induction of HIF-1 $\alpha$ in many cancer types results in several consequences that could enable tumour cells to survive and continue to proliferate.

Surprisingly, not all tumours that exhibit HIF-1 $\alpha$ overexpression have been found to be associated with decreased patient survival rates (Ref. 66). For example, in early-stage squamous cell carcinoma of the oral floor HIF- $1 \alpha$ overexpression is associated with improved survival rates (Ref. 66). This difference may arise from the fact that HIF-1 $\alpha$ could function by having a dual role in early carcinogenesis. On the one hand, HIF-1 $\alpha$ promotes tumour angiogenesis and cell survival when mediating an adaptive response, while on the other hand, in response to cellular stress HIF- $1 \alpha$ cooperates with the apoptotic machinery (via induction of apoptotic genes or crosstalk to p53) to mediate tumour cell death (Ref. 67). Indeed, the function of the HIFs in tumour progression might depend on the cell type and cellular context as well as the stage of carcinogenesis, and further work is needed to clarify this in order to establish when best to target the HIF pathway in cancer and whether certain cancer types would prove more or less sensitive to a HIF inhibitor.

\section{Strategies to target the HIF pathway in cancer}

In recent years, several strategies have been developed to identify direct and indirect inhibitors of HIF- $\alpha$ that function by blocking HIF- $\alpha$ (HIF- $1 \alpha$ or HIF-2 $\alpha$ ) expression levels and/or HIF (HIF-1 or HIF-2) activity. These include cell-based reporter screens, antisense approaches, targeting key protein-protein interactions, increasing HIF- $1 \alpha$ protein turnover or utilising a HIF oligonucleotide decoy (Table 1). In addition, therapeutic exploitation of other key pathways and mechanisms that are known to regulate HIF- $1 \alpha$ protein availability (stability and synthesis) and HIF-1 activity could also potentially be utilised to target the HIF pathway in cancer (Fig. 4). While the HIF transcriptional complex itself is a challenging therapeutic target, blockade of the HIF pathway and inhibition of HIF- $\alpha$ expression is therapeutically attractive because of its pivotal role in driving angiogenesis and tumour progression. Overexpression of HIF- $1 \alpha$ in many cancers and deregulation of HIF activity offers a degree of selectivity for tumour cells over normal tissue (Ref. 68), and blocking HIF- $1 \alpha$ especially when in combination with conventional therapies has a significant impact on tumour growth (Ref. 69).

\section{Targeting HIF-1 $\alpha$ directly}

As it functions as part of a transcriptional complex, targeting HIF- $1 \alpha$ directly is challenging. Specific antisense approaches have been used to reduce HIF- $1 \alpha$ expression and transcriptional activity (Ref. 70), and a dominant negative form of HIF- $1 \alpha$ has also been used (Ref. 71). Another approach is to inhibit HIF-1 transcriptional activity by blocking HIF-1 $\alpha$ protein-protein interactions (Ref. 72). For example, the binding between HIF- $1 \alpha$ and the coactivator p300/CBP, and hence hypoxia-inducible transcription, has been attenuated by retroviral expression of a polypeptide (Ref. 73), by the smallmolecule chetomin (Refs 13, 74) or by the use of the indazole compound YC-1 (Refs 75, 76). In addition, small molecules such as rolitetracycline (a semisynthetic pyrrolidnomethyltetracycline) that block HIF$1 \alpha-$ HIF- $1 \beta$ dimerisation by targeting the PAS domain offer a strategy to block HIF-1mediated activity in tumour cells by inhibiting the formation of the HIF-1 complex (Ref. 77).

\section{Targeting HIF-1 $\alpha$ expression and/or HIF-1 activity indirectly \\ Prolyl hydroxylases}

Mechanisms that regulate HIF- $1 \alpha$ protein stability provide indirect means to target $\mathrm{HIF}-1 \alpha$ protein 
Table 1. Strategies to identify inhibitors of HIF-1 $\alpha$ and the HIF pathway

\begin{tabular}{|c|c|c|c|}
\hline Strategies & Agents & Mechanism & Refs \\
\hline \multirow{8}{*}{$\begin{array}{l}\text { Cell-based (HRE } \\
\text { reporter) }\end{array}$} & Topotecan (Hycamtin) & Topoisomerase-1 inhibitor & 102,103 \\
\hline & NSC-134754 & Translation inhibitor & 100 \\
\hline & 103D5R & Translation inhibitor & 101 \\
\hline & Echinomycin & DNA binding & 154 \\
\hline & DJ12 & DNA binding/transactivation & 155 \\
\hline & Alkyliminophenylacetate & Mitochondria & 156 \\
\hline & $\begin{array}{l}\text { Anthracycline chemotherapeutic } \\
\text { agents }\end{array}$ & DNA binding & 157 \\
\hline & Cardiac glycosides & $\begin{array}{l}\text { HIF- } 1 \alpha \text { protein synthesis } \\
\text { inhibitors }\end{array}$ & 117 \\
\hline Dominant negative & dnHIF-1 & $\begin{array}{l}\text { Inhibition of functional HIF-1 } \\
\text { formation }\end{array}$ & 71 \\
\hline \multirow[t]{2}{*}{ Antisense } & SPC-2968 (ENZ-2968) & $\begin{array}{l}\text { DNA-RNA interaction } \\
\text { (expression inhibitor) }\end{array}$ & 158 \\
\hline & $\mathrm{RX}-0047$ & $\begin{array}{l}\text { DNA-RNA interaction } \\
\text { (expression inhibitor) }\end{array}$ & 159 \\
\hline \multirow[t]{2}{*}{$\begin{array}{l}\text { Protein-protein } \\
\text { interaction }\end{array}$} & Chetomin & $\begin{array}{l}\text { p300-HIF-1 } \alpha \text { interaction } \\
\text { inhibitor }\end{array}$ & 13,74 \\
\hline & Rolitetracycline & $\begin{array}{l}\text { HIF-1 } \alpha-\mathrm{HIF}-1 \beta \text { (ARNT } \\
\text { interaction inhibitor) }\end{array}$ & 72,77 \\
\hline \multirow[t]{3}{*}{ Other } & KRH102053 & PHD2 activator & 79 \\
\hline & HIF oligonucleotide decoy & Binds to and inactivates HIF- $1 \alpha$ & 160 \\
\hline & Intrabodies (IB-AG2) & $\begin{array}{l}\text { Inhibits HIF-1 transcriptional } \\
\text { activity }\end{array}$ & 219 \\
\hline
\end{tabular}

levels in tumour cells (Fig. 4). For example, overexpression of PHDs (Ref. 78) enhances HIF$1 \alpha$ protein turnover and results in reduced HIF$1 \alpha$ protein availability in tumour cells. Thus, small-molecule activators of the PHDs - such as KRH1020053 - have been developed to reduce HIF-1 $\alpha$ protein levels in tumour cells (Ref. 79). Alternatively, genetic blockade of SIAH2, which encodes an E3 ubiquitin ligase that ubiquinates PHD2 in hypoxia, leads to reduced HIF- $1 \alpha$ availability (Ref. 80) and provides another potential mechanism for targeting HIF- $1 \alpha$ protein stability (Ref. 81).

\section{The p53 tumour suppressor protein}

Understanding the relationship between HIF and other key signalling pathways can provide valuable therapeutic insight for developing strategies to target HIF indirectly (Fig. 4). For example, considerable progress has been made to our understanding of the molecular mechanisms by which HIF is regulated by the tumour suppressor protein p53, a transcription factor that plays a crucial role in monitoring cellular integrity. When the cell is stressed, p53 protein rapidly accumulates leading to either cell cycle arrest or apoptosis. However, p53 is mutated in over $50 \%$ of human cancers (Ref. 82). Mutated p53 is unable to transactivate downstream targets and is associated with malignant progression and metastasis (Refs 83, 84). While hypoxia induces cells to undergo p53-dependent apoptosis under some circumstances, cancer cells with dysregulated p53 function are able to survive (Refs 85, 86, 87).

p53 is involved in negatively regulating HIF- $1 \alpha$ expression and HIF-1 activity (Refs 88, 89, 90, 91). While the molecular crosstalk between HIF-1 and p53 is complex, HIF- $1 \alpha$ has been observed to bind to p53 in some cellular settings (Ref. 88). An in vitro study has provided biophysical evidence supporting the direct binding of p53 with 
Figure 4. Strategies to target the HIF-1 pathway in cancer. (a-c) Several strategies to specifically target hypoxia-inducible factor $1 \alpha(\mathrm{HIF}-1 \alpha)$ protein levels and HIF-1 activity in cancer cells have been developed (shown in red), including: (a) inhibition of protein-protein interactions (e.g. HIF-1 dimerisation or coactivator recruitment); (b) inhibition of HRE transcriptional activity (e.g. using small-molecules identified in HRE cellbased reporter screens); and (c) activation of HIF-1 $\alpha$ protein degradation (e.g. using PHD activators). (d-f) In addition, therapeutic targets currently in development that are known regulators of the HIF-1 pathway provide an alternative means for blocking HIF-1 $\alpha$ protein availability (stability and synthesis) and HIF-1 activity in tumour cells (shown in green), including: (d) inhibition of signalling pathways upstream of HIF (PI3K-AKT-mTOR/HDM2 and Ras-MAPK); (e) inhibition of chaperone proteins (e.g. HSP90); and (f) activation of the tumour suppressor p53. Direct downstream targets are indicated by solid lines, and downstream effectors are indicated by dashed lines. Abbreviations: AKT, AKT/protein kinase B; HDM2, human homologue of MDM2 (E3 ubiquitin ligase; p53-binding protein); HRE, hypoxia-response element; HSP90, heat shock protein 90; MAPK, mitogen-activated protein kinase (also known as extracellular-signalregulated kinase, ERK); MEK, MAPK kinase; mTOR, mammalian target of rapamycin; p300/CBP, p300/CREB-binding protein; PHD, prolyl hydroxylase domain protein; PI3K, phosphoinositide 3-kinase; pVHL, von Hippel-Lindau tumour suppressor protein; RTK, receptor tyrosine kinase; SIAH1a/2, seven in absentia homologue 1a/2; Ub, ubiquitination. 
HIF- $1 \alpha$ via the ODD domain within HIF- $1 \alpha$ (Ref. 92). This interaction was originally proposed to result in p53 stabilisation (Ref. 88) as well as inhibition of HIF-1 activity (Refs 88, $89,92,93)$. However, further work has shown that HIF-1 $\alpha$ induced in hypoxia does not affect p53 stabilisation (Ref. 90), and it has been proposed that the direct interaction of p53 with HIF-1 $\alpha$ leads to HDM2-mediated degradation of HIF-1 $\alpha$ (Ref. 90), resulting in hypoxiainduced p53-dependent apoptosis (Refs 88, 89, 94). Indeed, recent work has shown that the apoptotic function of p53 can be regulated by the status of HIF-1 $\alpha$ in cells and that blocking HIF-1 $\alpha$ expression can drive p53-mediated tumour cell death in hypoxia (Ref. 91).

It has been suggested that p53 can block HIF-1 transcriptional activity by competing with HIF- $1 \alpha$ for p300 (Ref. 93). p53, which itself is a transcription factor, requires the recruitment of p300 for its activity. Using an HRE-luciferase reporter assay to measure the transactivation of HIF-1, it has been demonstrated that low levels of exogenous p53 can block HIF-1 transcriptional activity and this effect can be relieved by overexpression of p300 in the cell (Ref. 93). This competitive binding of p53 for p300 was also confirmed in a separate in vitro transcription assay (Ref. 93). While low levels of p53 can affect HIF-1 activity, high levels of p53 have been reported by several independent studies to block HIF- $1 \alpha$ protein accumulation (Refs 54, 90, 93, 94). Furthermore, loss of p53 has been observed to correlate with increased HIF-1 $\alpha$ protein level and increased HIF1 activity (Ref. 90). Forced expression of HIF-1 $\alpha$ in p53-expressing tumour cells upregulates VEGF expression (Refs 90, 95), neovascularisation and the growth of tumour xenografts (Ref. 90). Taken together, these studies clearly demonstrate that p53 negatively regulates HIF-1 transcriptional activity and HIF-1 $\alpha$ protein levels and highlights the possibility that reactivating p53 may provide a means to target the HIF pathway in cancer (Fig. 4).

Efforts have been made to identify agents that reactivate mutant p53 (Refs 96, 97) or activate wild-type p53 (Refs 98, 99) in cancer cells (Table 2). Recently, a small-molecule activator of p53, RITA (reactivation of p53 and induction of tumour cell apoptosis), was demonstrated to induce and activate p53, resulting in tumour cell apoptosis (Refs 91, 98). Interestingly, RITA was also observed to block HIF-1 $\alpha$ expression, resulting in downregulation of VEGF expression, and antiangiogenic effects in vivo (Ref. 91). The ability of a single agent to activate p53-dependent apoptosis and simultaneously suppress tumour angiogenesis represents a novel and promising therapeutic strategy for targeting the HIF pathway in solid tumours (Ref. 91).

\section{Other mechanisms for targeting HIF}

Several high-throughput cell-based screening approaches using HRE-luciferase reporter systems have identified numerous HIF- $1 \alpha$ small-molecule inhibitors that block tumour cell growth by blocking HIF- $1 \alpha$ protein accumulation and HIF activity (Refs 100, 101), although their mechanism of actions remain to be understood. For example, topotecan - a topoisomerase inhibitor and known cytotoxic agent (Table 2) - was found to block HRE activity in a cell-based screen and was subsequently shown to suppress HIF- $1 \alpha$ protein translation (Refs 102, 103). This inhibitor is currently being launched in the clinic to target ovarian and small-cell lung cancer cells. Interestingly, PX-478, another inhibitor of HIF-1 $\alpha$ protein translation (although not identified through a cell-based HRE-luciferase reporter screen) is in Phase I clinical trials (Refs 104, 105, 106); however, the precise cellular target of PX-478 that is responsible for HIF- $1 \alpha$ inhibition is not certain, and thus the development of clear clinical endpoints may prove challenging.

In addition to strategic efforts being developed to target the HIF pathway, many recognised anticancer drugs that target known regulators of HIF function have also been shown to block HIF-1 $\alpha$ protein levels and/or HIF-1 activity (Table 2). For example, the histone deacetylase (HDAC) inhibitors trichostatin A and FK228 inhibit HIF-1 $\alpha$ induction and HIF-1 activity (Refs 107, 108, 109, 110, 111). Geldanamycin and 17-AAG, which are HSP90 antagonists, are also effective at inhibiting HIF- $1 \alpha$ expression levels (Refs 112, 113, 114, 115, 116), and recent work has identified digoxin as a potent inhibitor of HIF-1 $\alpha$ synthesis and tumour growth (Ref. 117). Other tractable HIF regulators that have emerged recently include c-Myc (Refs 118, 119), c-Met (Refs 120, 121, 122) and components of the Ras (Ref. 123) and Wnt (Refs 124, 125, 126) 
Table 2. Anticancer agents that decrease HIF-1 $\alpha$ and target the HIF-1 pathway

\section{Target pathways/mechanisms}

Signalling

Receptor tyrosine kinases

Ras-MAPK pathway

PI3K-AKT pathway

mTOR

HSP9O

Soluble guanylyl cyclase (sGS)

coX-2

Histone deacetylase

Microtubules

Microtubule destabilisers

Microtubule stabiliser

DNA binding/damage/cytotoxic

DNA binding

p53-HDM2 interaction

\section{Agents}

Genistein

(VEGFR)-bevacizumab (avastin)

(EGFR)-Iressa/gefitinib

Tarceva/erlotinib

C225/cetuximab

PD98059

BAY 43-9006 (sorafenib)

LY294002

Wortmannin

Nelfinavir (HIV protease inhibitor)

Silibinin

NO-sulindac

Rapamycin

Temsirolimus/CC1-779

Everolimus/RAD001

Geldanamycin

17AAG

Apigenin

YC-1 (sGC stimulator)

NS398

Ibuprofen

SAHA

FK228

LAQ824

Trichostatin A

Curcumin

EF24

2-ME2

ENMD-1198

Taxol

Echinomycin

Polyamide

DJ12

Doxorubicin

Cisplatin

Nutlins

RITA

\section{Refs}

$161,162,163,164$

165

166, 167, 168

168

75,167

169, 170

171

162

162

172,173

174

175

176,177

178

179, 180

112,113

$114,115,116$

$181,182,183,184$

$70,75,76,185,186,187,188$

189, 190, 191

192

193

$107,108,109,110$

194

111

195

195

196, 197, 198

199, 200

201

154, 202

203

155

204

204

99, 205

91 
Table 2. Anticancer agents that decrease HIF-1 $\alpha$ and target the HIF-1 pathway (continued)

\begin{tabular}{lll}
\hline Target pathways/mechanisms & Agents & Refs \\
Translation & PX-478 & $104,105,106,206,207,208$ \\
& Tunicamycin & 209,210 \\
& UVC irradiation & 211 \\
Topoisomerase I/II & Topotecan & $102,103,212$ \\
& NSC-644221 & 213 \\
DNA replication/transcription & & \\
Topoisomerase I/II & Irinotecan & $102,176,214$ \\
Mitochondria & Alkylimino- phenylacetate & 156 \\
& Antimycin & 215 \\
& Rotenone & 216,217 \\
& Myxothiazol & 216 \\
Others & & \\
Thioredoxin redox system & Pleurotin & 218 \\
RNA polymerase & TAS106 (ECyd) & 220 \\
DNA synthesis/repair & TS-1 & 221 \\
Multiple signalling pathways & Resveratrol & 222 \\
(Ras-MAPK; P13K-AKT) & & \\
CDK & Flavopiridol & 223 \\
Abbreviations: CDK, cyclin-dependent kinase; COX-2, cyclooxygenase 2; EGFR, epidermal growth factor \\
receptor; HIF, hypoxia-inducible factor;
\end{tabular}

pathways. A thorough evaluation of how these regulators influence HIF function in cancer may provide further insights into targeting the HIF pathway.

\section{Which HIF- $\alpha$ subunit to inhibit?}

When developing new agents to target HIF- $\alpha$ in cancer, the specific effects mediated by a particular HIF- $\alpha$ (HIF- $1 \alpha$ or HIF- $2 \alpha$ ) isoform in different cell types should be taken into consideration (Ref. 39). Targeting a single HIF- $\alpha$ subunit may not necessarily give the desired effects because it has been demonstrated that different subunits may play distinct roles in different cellular contexts (Refs 39, 41, 127, 128). For example, using siRNA techniques, HIF- $1 \alpha$ was reported to be the primary hypoxia-induced transcription factor in breast carcinoma and endothelial cells (Ref. 129), whereas in renal carcinoma cells HIF- $2 \alpha$ was shown to be primarily responsible for the induction of hypoxic genes (Ref. 39). These findings were supported by two separate studies that confirmed HIF-1 $\alpha$ primarily regulates the transcription of hypoxia-regulated target genes in MCF-7 breast carcinoma cells, while HIF- $2 \alpha$ controls the transcription of target genes such as glucose transporter 1 (GLUT-1) as well as tumour progression in renal carcinoma cells that have lost pVHL function (Refs 39, 43, 130). Interestingly, in pVHL-defective renal carcinoma cells, HIF-1 $\alpha$ was found to play a tumour suppressor role. Because the tumour-promoting HIF- $\alpha$ subunit in these cell lines is HIF- $2 \alpha$ (Refs 43, 118, 130), treatment targeting this subunit may be more beneficial (Ref. 39). It is important to assess whether targeting both HIF$1 \alpha$ and HIF- $2 \alpha$ or either subunit selectively will provide better therapeutic effects in vivo.

Recent work has revealed that $\mathrm{pVHL}$-defective renal carcinoma cells can be further subdivided into tumours with detectable HIF- $1 \alpha$ and HIF- $2 \alpha$, or just HIF- $2 \alpha$ exclusively (Ref. 119). Accordingly, tumours with detectable HIF-1 $\alpha$ and HIF- $\alpha$ exhibit enhanced activation of AKT-mTOR and MAPK pathways and $\gamma \mathrm{H} 2 \mathrm{AX}$ 
(phosphorylated histone H2AX) accumulation, whereas tumours with only HIF- $2 \alpha$ expression display increased c-Myc activity. The identified oncogenic pathways associated with these tumours may enable the strategic selection of combined targeted therapies to be used against these different tumour subtypes.

Translation of HIF inhibitors into the clinic Hypoxic tumours are usually resistant to radiotherapy, as a result of the low level of oxygen molecules available to generate DNA strand breaks, and to chemotherapy, because of their slow divisional rate, abnormal vasculature and the upregulation of many genes that contribute to their aggressive phenotype. However, blocking HIF-1 $\alpha$ renders tumour cells more susceptible to radiotherapy and conventional chemotherapeutic agents (Refs 13, 14). The recent advances to our understanding of the HIF pathway have helped us to clarify its role in cancer and consequently enable the identification and design of novel therapies. Inhibitors that target the HIF pathway directly or indirectly are attractive and should prove useful in the treatment of most solid tumours including breast, prostate and renal carcinomas. Understanding the mechanism of action of different HIF pathway inhibitors is of particular importance when deciding when and how they would best be used in combination.

\section{Which cancer types to target?}

HIF-1 $\alpha$ protein levels can be used as a prognosis marker in various cancers (Refs 131, 132, 133, 134), as well as a predictive biomarker when designing new treatment regimes. Patients with VHLmutated sporadic clear-cell renal carcinomas exhibit high basal HIF- $\alpha$ expression and subsequently increased expression of VEGF and platelet-derived growth factor (PDGF). To date, the small-molecule tyrosine kinase inhibitors sunitinib and sorafenib that block VEGF and PDGF signalling have been the only agents shown to stabilise the disease, although increases in overall survival are disappointingly low (Refs 69, 135, 136, 137). Both sunitinib and sorafenib have been approved for the treatment of renal cell carcinoma, where sunitinib is currently recommended as a first-line treatment and sorafenib as a second-line treatment option for people with advanced metastatic renal cell carcinoma (Refs 69, 138). Clinical trials are under way to investigate the efficacy of these drugs in combination with conventional treatments or other small-molecule inhibitors and antibody therapies. Interestingly, a recent cell-based assay approach using renal carcinoma cells has identified STF-62247, an agent that functions to selectively induce cytotoxic and antitumour effects in pVHLdeficient renal carcinoma cells by inducing autophagy (Ref. 139). The identification of STF62247 illustrates the possibility of developing therapeutic agents that specifically target pVHL-deficient renal cancers (with high basal HIF- $\alpha$ expression), which account for around $75 \%$ of renal cell carcinomas (Ref. 139). Moreover, a pilot synthetic lethal screen has identified that inhibition of kinases such as CDK4/ 6 enhanced growth inhibition of pVHLdeficient renal cell carcinomas compared with matched pVHL-proficient renal cell carcinomas (Ref. 140), further highlighting those tractable targets for therapeutic intervention in renal cell carcinoma. It will be of particular interest to establish whether HIF inhibitors when used either alone or in combination with these other agents can provide a better therapeutic outcome for patients with advanced metastatic renal cell carcinoma.

\section{Imaging hypoxia as a clinical tool}

Effective imaging of hypoxia is important for cancer detection and diagnosis, assessment of therapy, as well as drug development. Imaging also provides a prognostic basis by which the effects of tumour hypoxia could be evaluated in personalised cancer treatment. For example, patients could be selected for hypoxia and high HIF-1 $\alpha$ protein levels in their tumours, in order to enter them into clinical trials involving HIF inhibitors.

Several direct and indirect methods for measuring hypoxia have been developed. Direct $\mathrm{pO}_{2}$ measurement can be performed by an Eppendorf probe (a polarographic needle microelectrode) by direct insertion into tissues (Refs 141, 142). Exogenous markers of hypoxia (such as pimonidazole and EF5) provide a more reliable measurement than using Eppendorf probes and can be used to detect the distribution of hypoxia in a small fraction of tumour (Refs 143, 144, 145). Positron emission tomography (PET) tracers such as $\left[{ }^{18} \mathrm{~F}\right]$ fluoromisonidazole have also been used 
to measure hypoxia throughout the body (Refs 146, 147, 148). PET imaging is sensitive and has a spatial and temporal resolution suitable for accessing the heterogeneity of local $\mathrm{pO}_{2}$. This technique was shown to have the ability to predict outcomes from radiation therapy by imaging hypoxic tissues (Refs 149, 150, 151, 152). Several magnetic resonance (MR)-based imaging (MRI) and spectroscopy strategies have been developed to assess tumour hypoxia directly or indirectly - namely ${ }^{19} \mathrm{~F}-\mathrm{MRI}$ and spectroscopy, high molecular weight dynamic contrast-enhanced MRI, electron paramagnetic resonance imaging and electron paramagnetic resonance oximetry. These methods can reliably and precisely reveal heterogeneity of oxygen distribution within tissues. As well as locating tumour and assessing treatment, MRI-based techniques can detect detailed metabolic and physiological information and PET imaging can reveal biochemical characteristics of the tumour, including metastases. With the preclinical development of many new HIF inhibitors being pursued currently, one challenge will be to define robust preclinical noninvasive imaging endpoints that are not only consistent with measurable effects on the HIF pathway in vivo, but that also directly relate to the mechanism of action and provide clear therapeutic insight with respect to the hypoxic tumour compartment.

\section{Conclusions}

Hypoxic tumours are usually resistant to killing by radiotherapy and conventional chemotherapies, rendering them highly aggressive and metastatic. Oxygen homeostasis in cells and the response to hypoxic stress is largely mediated by the HIF pathway. However, dysregulation of the HIF pathway occurs in many human cancers and usually correlates with a poor prognostic outcome using conventional treatments. Therefore, targeting the HIF pathway provides an attractive strategy to treat hypoxic and highly angiogenic tumours. The combination of HIF inhibitors with existing treatments or new targeted therapies may prove to be useful clinically.

However, the development of appropriate imaging strategies to accurately measure hypoxia in tumours along with the identification of suitable biomarker endpoints will accelerate the translation of new therapeutic combinations into the clinic as well as provide prognostic information that helps tailor specific treatments to different cancer types. HIF inhibitors are in preclinical and clinical development and these offer a novel and attractive approach for the treatment of solid tumours.

\section{Acknowledgements and funding}

We thank Dr Jan Bussink (Department of Radiation Oncology 874, Radboud University Nijmegen, The Netherlands) for kindly providing the data presented in Figure 1. We also thank Dr Yann Jamin (Institute of Cancer Research, Sutton, Surrey, UK) for his advice on imaging, and Prof. Patrick Maxwell (University College London, UK) for critical review of our manuscript. E.P. is funded by Cancer Research UK project grant C7358/A9958. We also thank the reviewers for their insightful comments and helpful suggestions.

\section{References}

1 Vaupel, P., Hockel, M. and Mayer, A. (2007) Detection and characterization of tumor hypoxia using pO2 histography. Antioxidants and Redox Signalling 9, 1221-1235

2 Hockel, M. et al. (1993) Intratumoral pO2 predicts survival in advanced cancer of the uterine cervix. Radiotherapy and Oncology 26, 45-50

3 Hockel, M. et al. (1996) Association between tumor hypoxia and malignant progression in advanced cancer of the uterine cervix. Cancer Research 56, 4509-4515

4 Hockel, M. et al. (1999) Hypoxic cervical cancers with low apoptotic index are highly aggressive. Cancer Research 59, 4525-4528

5 Hockel, M. and Vaupel, P. (2001) Tumor hypoxia: definitions and current clinical, biologic, and molecular aspects. Journal of the National Cancer Institute 93, 266-276

6 Hockel, M. et al. (1993) Tumor oxygenation: a new predictive parameter in locally advanced cancer of the uterine cervix. Gynecologic Oncology 51, 141-149

7 Wang, G.L. et al. (1995) Hypoxia-inducible factor 1 is a basic-helix-loop-helix-PAS heterodimer regulated by cellular $\mathrm{O} 2$ tension. Proceedings of the National Academy of Sciences of the United States of America 92, 5510-5514

8 Guillemin, K. and Krasnow, M.A. (1997) The hypoxic response: huffing and HIFing. Cell 89, 9-12 
9 Semenza, G.L. (2003) Targeting HIF-1 for cancer therapy. Nature Reviews Cancer 3, 721-732

10 Bos, R. et al. (2001) Levels of hypoxia-inducible factor-1 alpha during breast carcinogenesis. Journal of the National Cancer Institute 93, 309-314

11 Zhong, H. et al. (1999) Overexpression of hypoxiainducible factor-1alpha in common human cancers and their metastases. Cancer Research 59, 5830-5835

12 Maxwell, P.H. et al. (1997) Hypoxia-inducible factor-1 modulates gene expression in solid tumors and influences both angiogenesis and tumor growth. Proceedings of the National Academy of Sciences of the United States of America 94, 8104-8109

13 Staab, A. et al. (2007) Effects of HIF-1 inhibition by chetomin on hypoxia-related transcription and radiosensitivity in HT 1080 human fibrosarcoma cells. BMC Cancer 7, 213

14 Williams, K.J. et al. (2005) Enhanced response to radiotherapy in tumours deficient in the function of hypoxia-inducible factor-1. Radiotherapy and Oncology 75, 89-98

15 Moeller, B.J. et al. (2004) Radiation activates HIF1 to regulate vascular radiosensitivity in tumors: role of reoxygenation, free radicals, and stress granules. Cancer Cell 5, 429-441

16 Moeller, B.J. et al. (2005) Pleiotropic effects of HIF-1 blockade on tumor radiosensitivity. Cancer Cell $8,99-110$

17 Jiang, B.H. et al. (1996) Dimerization, DNA binding, and transactivation properties of hypoxia-inducible factor 1 . Journal of Biological Chemistry 271, 17771-17778

18 Li, H., Ko, H.P. and Whitlock, J.P. (1996) Induction of phosphoglycerate kinase 1 gene expression by hypoxia. Roles of Arnt and HIF1alpha. Journal of Biological Chemistry 271, 21262-21267

19 Fukuda, R. et al. (2002) Insulin-like growth factor 1 induces hypoxia-inducible factor 1-mediated vascular endothelial growth factor expression, which is dependent on MAP kinase and phosphatidylinositol 3-kinase signaling in colon cancer cells. Journal of Biological Chemistry 277, 38205-38211

20 Laughner, E. et al. (2001) HER2 (neu) signaling increases the rate of hypoxia-inducible factor 1alpha (HIF-1alpha) synthesis: novel mechanism for HIF-1-mediated vascular endothelial growth factor expression. Molecular and Cellular Biology 21, 3995-4004

21 Huang, L.E. et al. (1998) Regulation of hypoxiainducible factor 1alpha is mediated by an O2- dependent degradation domain via the ubiquitinproteasome pathway. Proceedings of the National Academy of Sciences of the United States of America 95, 7987-7992

22 Ivan, M. et al. (2001) HIFalpha targeted for VHLmediated destruction by proline hydroxylation: implications for O2 sensing. Science 292, 464-468

23 Jaakkola, P. et al. (2001) Targeting of HIF-alpha to the von Hippel-Lindau ubiquitylation complex by O2-regulated prolyl hydroxylation. Science 292, 468-472

24 Masson, N. et al. (2001) Independent function of two destruction domains in hypoxia-inducible factor-alpha chains activated by prolyl hydroxylation. EMBO Journal 20, 5197-5206

$25 \mathrm{Yu}$, F. et al. (2001) HIF-1alpha binding to VHL is regulated by stimulus-sensitive proline hydroxylation. Proceedings of the National Academy of Sciences of the United States of America 98, 9630-9635

26 Bruick, R.K. and McKnight, S.L. (2001) A conserved family of prolyl-4-hydroxylases that modify HIF. Science 294, 1337-1340

27 Epstein, A.C. et al. (2001) C. elegans EGL-9 and mammalian homologs define a family of dioxygenases that regulate HIF by prolyl hydroxylation. Cell 107, 43-54

28 Berra, E. et al. (2003) HIF prolyl-hydroxylase 2 is the key oxygen sensor setting low steady-state levels of HIF-1alpha in normoxia. EMBO Journal 22, 4082-4090

29 Kallio, P.J. et al. (1998) Signal transduction in hypoxic cells: inducible nuclear translocation and recruitment of the $\mathrm{CBP} / \mathrm{p} 300$ coactivator by the hypoxia-inducible factor-1alpha EMBO Journal 17, 6573-6586

30 Wang, G.L. and Semenza, G.L. (1993) General involvement of hypoxia-inducible factor 1 in transcriptional response to hypoxia. Proceedings of the National Academy of Sciences of the United States of America 90, 4304-4308

31 Hewitson, K.S. et al. (2002) Hypoxia-inducible factor (HIF) asparagine hydroxylase is identical to factor inhibiting HIF (FIH) and is related to the cupin structural family. Journal of Biological Chemistry 277, 26351-26355

32 Lando, D. et al. (2002) FIH-1 is an asparaginyl hydroxylase enzyme that regulates the transcriptional activity of hypoxia-inducible factor. Genes and Development 16, 1466-1471

33 Lando, D. et al. (2002) Asparagine hydroxylation of the HIF transactivation domain a hypoxic switch. Science 295, 858-861 
34 McNeill, L.A. et al. (2002) Hypoxia-inducible factor asparaginyl hydroxylase (FIH-1) catalyses hydroxylation at the beta-carbon of asparagine-803. The Biochemical Journal 367, 571-575

35 Mahon, P.C., Hirota, K. and Semenza, G.L. (2001) FIH-1: a novel protein that interacts with HIF1alpha and VHL to mediate repression of HIF-1 transcriptional activity. Genes and Development $15,2675-2686$

36 Semenza, G.L. (1999) Regulation of mammalian O2 homeostasis by hypoxia-inducible factor 1 . Annual Review of Cell and Developmental Biology 15, 551-578

37 Bardos, J.I. and Ashcroft, M. (2005) Negative and positive regulation of HIF-1: a complex network. Biochimica et Biophysica Acta 1755, 107-120

38 Wiesener, M.S. et al. (1998) Induction of endothelial PAS domain protein-1 by hypoxia: characterization and comparison with hypoxiainducible factor-1alpha. Blood 92, 2260-2268

39 Carroll, V.A. and Ashcroft, M. (2006) Role of hypoxia-inducible factor (HIF)-1alpha versus HIF-2alpha in the regulation of HIF target genes in response to hypoxia, insulin-like growth factor-I, or loss of von Hippel-Lindau function: implications for targeting the HIF pathway. Cancer Research 66, 6264-6270

40 Compernolle, V. et al. (2002) Loss of HIF-2alpha and inhibition of VEGF impair fetal lung maturation, whereas treatment with VEGF prevents fatal respiratory distress in premature mice. Nature Medicine 8, 702-710

$41 \mathrm{Hu}, \mathrm{C} . J$. et al. (2003) Differential roles of hypoxiainducible factor 1alpha (HIF-1alpha) and HIF-2alpha in hypoxic gene regulation. Molecular and Cellular Biology 23, 9361-9374

42 Krieg, M. et al. (2000) Up-regulation of hypoxiainducible factors HIF-1alpha and HIF-2alpha under normoxic conditions in renal carcinoma cells by von Hippel-Lindau tumor suppressor gene loss of function. Oncogene 19, 5435-5443

43 Raval, R.R. et al. (2005) Contrasting properties of hypoxia-inducible factor 1 (HIF-1) and HIF-2 in von Hippel-Lindau-associated renal cell carcinoma. Molecular and Cellular Biology 25, 5675-5686

44 Maxwell, P.H. et al. (1999) The tumour suppressor protein VHL targets hypoxia-inducible factors for oxygen-dependent proteolysis. Nature 399, 271-275

45 Maynard, M.A. et al. (2003) Multiple splice variants of the human HIF-3 alpha locus are targets of the von Hippel-Lindau E3 ubiquitin ligase complex. Journal of Biological Chemistry 278, 11032-11040

46 Makino, Y. et al. (2001) Inhibitory PAS domain protein is a negative regulator of hypoxia-inducible gene expression. Nature 414, 550-554

47 Makino, Y. et al. (2007) Transcriptional upregulation of inhibitory PAS domain protein gene expression by hypoxia-inducible factor 1 (HIF-1): a negative feedback regulatory circuit in HIF-1-mediated signaling in hypoxic cells. Journal of Biological Chemistry 282, 14073-14082

48 Briere, J.J. et al. (2006) Tricarboxylic acid cycle dysfunction as a cause of human diseases and tumor formation. American Journal of Physiology Cell Physiology 291, C1114-1120

49 Pollard, P.J. et al. (2005) Accumulation of Krebs cycle intermediates and over-expression of HIF1alpha in tumours which result from germline $\mathrm{FH}$ and SDH mutations. Human Molecular Genetics 14, 2231-2239

50 Berra, E., Pages, G. and Pouyssegur, J. (2000) MAP kinases and hypoxia in the control of VEGF expression. Cancer and Metastasis Reviews 19, 139-145

51 Karni, R. et al. (2002) Activated pp60c-Src leads to elevated hypoxia-inducible factor (HIF)-1alpha expression under normoxia. Journal of Biological Chemistry 277, 42919-42925

52 Lee, B.L. et al. (2008) A hypoxia-independent upregulation of hypoxia-inducible factor- 1 by AKT contributes to angiogenesis in human gastric cancer. Carcinogenesis 29, 44-51

53 Zhong, H. et al. (2000) Modulation of hypoxiainducible factor 1alpha expression by the epidermal growth factor/phosphatidylinositol 3-kinase/PTEN/AKT/FRAP pathway in human prostate cancer cells: implications for tumor angiogenesis and therapeutics. Cancer Research $60,1541-1545$

54 Bardos, J.I. and Ashcroft, M. (2004) Hypoxiainducible factor-1 and oncogenic signalling. Bioessays 26, 262-269

55 Zundel, W. et al. (2000) Loss of PTEN facilitates HIF-1-mediated gene expression. Genes and Development 14, 391-396

56 Miyake, K. et al. (2008) Expression of hypoxiainducible factor-1alpha, histone deacetylase 1, and metastasis-associated protein 1 in pancreatic carcinoma: correlation with poor prognosis with possible regulation. Pancreas 36, e1-9 
57 Koukourakis, M.I. et al. (2002) Hypoxia-inducible factor (HIF1A and HIF2A), angiogenesis, and chemoradiotherapy outcome of squamous cell head-and-neck cancer. International Journal of Radiation Oncology Biology Physics 53, 1192-1202

58 Winter, S.C. et al. (2006) The relation between hypoxia-inducible factor (HIF)-1alpha and HIF-2alpha expression with anemia and outcome in surgically treated head and neck cancer. Cancer 107, 757-766

59 Aebersold, D.M. et al. (2001) Expression of hypoxia-inducible factor-1alpha: a novel predictive and prognostic parameter in the radiotherapy of oropharyngeal cancer. Cancer Research 61, 2911-2916

60 Bos, R. et al. (2003) Levels of hypoxia-inducible factor-1alpha independently predict prognosis in patients with lymph node negative breast carcinoma. Cancer 97, 1573-1581

61 Gruber, G. et al. (2004) Hypoxia-inducible factor 1 alpha in high-risk breast cancer: an independent prognostic parameter? Breast Cancer Research 6, R191-198

62 Klatte, T. et al. (2007) Hypoxia-inducible factor 1 alpha in clear cell renal cell carcinoma. Clinical Cancer Research 13, 7388-7393

63 Osada, R. et al. (2007) Expression of hypoxiainducible factor 1alpha, hypoxia-inducible factor 2alpha, and von Hippel-Lindau protein in epithelial ovarian neoplasms and allelic loss of von Hippel-Lindau gene: nuclear expression of hypoxia-inducible factor 1alpha is an independent prognostic factor in ovarian carcinoma. Human Pathology 38, 1310-1320

$64 \mathrm{Ke}, \mathrm{H} . L$. et al. (2008) Overexpression of hypoxiainducible factor-1alpha predicts an unfavorable outcome in urothelial carcinoma of the upper urinary tract. International Journal of Urology 15, 200-205

65 Talks, K.L. et al. (2000) The expression and distribution of the hypoxia-inducible factors HIF1alpha and HIF-2alpha in normal human tissues, cancers, and tumor-associated macrophages. American Journal of Pathology 157, 411-421

66 Fillies, T. et al. (2005) HIF1-alpha overexpression indicates a good prognosis in early stage squamous cell carcinomas of the oral floor. BMC Cancer 5, 84

67 Sumiyoshi, Y. et al. (2006) Overexpression of hypoxia-inducible factor 1alpha and p53 is a marker for an unfavorable prognosis in gastric cancer. Clinical Cancer Research 12, 5112-5117
68 Maxwell, P.H. (2005) The HIF pathway in cancer. Seminars in Cell and Developmental Biology 16, 523-530

69 Bastien, L. et al. (2009) Targeted therapies in metastatic renal cancer in 2009. BJU International $103,1334-42$

70 Yeo, E.J., Chun, Y.S. and Park, J.W. (2004) New anticancer strategies targeting HIF-1. Biochemical Pharmacology 68, 1061-1069

71 Chen, J. et al. (2003) Dominant-negative hypoxiainducible factor- 1 alpha reduces tumorigenicity of pancreatic cancer cells through the suppression of glucose metabolism. American Journal of Pathology 162, 1283-1291

72 Zinzalla, G. and Thurston, D.E. (2009) Targeting protein-protein interactions for therapeutic intervention: a challenge for the future. Future Medicinal Chemistry 1, 65-93

73 Kung, A.L. et al. (2000) Suppression of tumor growth through disruption of hypoxia-inducible transcription. Nature Medicine 6, 1335-1340

74 Kung, A.L. et al. (2004) Small molecule blockade of transcriptional coactivation of the hypoxiainducible factor pathway. Cancer Cell 6, 33-43

75 Li, S.H. et al. (2008) A novel mode of action of YC-1 in HIF inhibition: stimulation of FIH-dependent p300 dissociation from HIF-1\{alpha\}. Molecular Cancer Therapeutics 7, 3729-3738

76 Yeo, E.J. et al. (2003) YC-1: a potential anticancer drug targeting hypoxia-inducible factor 1 . Journal of the National Cancer Institute 95, 516-525

77 Park, E.J. et al. (2006) Targeting the PAS-A domain of HIF-1alpha for development of small molecule inhibitors of HIF-1. Cell Cycle 5, 1847-1853

78 Erez, N. et al. (2003) Expression of prolylhydroxylase-1 (PHD1/EGLN2) suppresses hypoxia inducible factor-1alpha activation and inhibits tumor growth. Cancer Research 63, 8777-8783

79 Choi, H.J. et al. (2008) Rapid degradation of hypoxia-inducible factor-1alpha by KRH10 2053, a new activator of prolyl hydroxylase 2 . British Journal of Pharmacology 154, 114-125

80 Nakayama, K. et al. (2004) Siah2 regulates stability of prolyl-hydroxylases, controls HIFlalpha abundance, and modulates physiological responses to hypoxia. Cell 117, 941-952

81 Moller, A. et al. (2009) Inhibition of Siah ubiquitin ligase function. Oncogene 28, 289-296

82 Soussi, T. and Lozano, G. (2005) p53 mutation heterogeneity in cancer. Biochemical and Biophysical Research Communications 331, 834-842

83 Levine, A.J. (1997) p53 the cellular gatekeeper for growth and division. Cell 88, 323-331 
84 Vousden, K.H. and Lane, D.P. (2007) p53 in health and disease. Nature Reviews Molecular Cell Biology 8, 275-283

85 Denko, N.C. et al. (2000) p53 checkpoint-defective cells are sensitive to $X$ rays, but not hypoxia. Experimental Cell Research 258, 82-91

86 Giaccia, A.J. and Kastan, M.B. (1998) The complexity of p53 modulation: emerging patterns from divergent signals. Genes and Development 12, 2973-2983

87 Graeber, T.G. et al. (1996) Hypoxia-mediated selection of cells with diminished apoptotic potential in solid tumours. Nature 379, 88-91

88 An, W.G. et al. (1998) Stabilization of wild-type p53 by hypoxia-inducible factor 1alpha. Nature 392, 405-408

89 Blagosklonny, M.V. et al. (1998) p53 inhibits hypoxia-inducible factor-stimulated transcription. Journal of Biological Chemistry 273, 11995-11998

90 Ravi, R. et al. (2000) Regulation of tumor angiogenesis by p53-induced degradation of hypoxia-inducible factor 1alpha. Genes and Development 14, 34-44

91 Yang, J. et al. (2009) Small molecule activation of p53 blocks HIF-1\{alpha\} and VEGF expression in vivo and leads to tumor cell apoptosis in normoxia and hypoxia. Molecular and Cellular Biology 29, 2243-2253

92 Sanchez-Puig, N., Veprintsev, D.B. and Fersht, A.R. (2005) Binding of natively unfolded

HIF-1alpha ODD domain to p53. Molecular Cell 17, 11-21

93 Schmid, T. et al. (2004) p300 relieves p53-evoked transcriptional repression of hypoxia-inducible factor-1 (HIF-1). The Biochemical Journal 380, 289-295

94 Chen, D. et al. (2003) Direct interactions between HIF-1 alpha and Mdm2 modulate p53 function. Journal of Biological Chemistry 278, 13595-13598

95 Nieminen, A.L. et al. (2005) Mdm2 and HIF-1alpha interaction in tumor cells during hypoxia. Journal of Cellular Physiology 204, 364-369

96 Bykov, V.J. and Wiman, K.G. (2003) Novel cancer therapy by reactivation of the $\mathrm{p} 53$ apoptosis pathway. Annals of Medicine 35, 458-465

97 Foster, B.A. et al. (1999) Pharmacological rescue of mutant p53 conformation and function. Science 286, 2507-2510

98 Issaeva, N. et al. (2004) Small molecule RITA binds to $\mathrm{p} 53$, blocks p53-HDM-2 interaction and activates p53 function in tumors. Nature Medicine $10,1321-1328$
99 Vassilev, L.T. (2004) Small-molecule antagonists of p53-MDM2 binding: research tools and potential therapeutics. Cell Cycle 3, 419-421

100 Chau, N.M. et al. (2005) Identification of novel small molecule inhibitors of hypoxia-inducible factor-1 that differentially block hypoxiainducible factor- 1 activity and hypoxia-inducible factor-1alpha induction in response to hypoxic stress and growth factors. Cancer Research 65, 4918-4928

101 Tan, C. et al. (2005) Identification of a novel smallmolecule inhibitor of the hypoxia-inducible factor 1 pathway. Cancer Research 65, 605-612

102 Rapisarda, A. et al. (2002) Identification of small molecule inhibitors of hypoxia-inducible factor 1 transcriptional activation pathway. Cancer Research 62, 4316-4324

103 Rapisarda, A. et al. (2004) Schedule-dependent inhibition of hypoxia-inducible factor-1alpha protein accumulation, angiogenesis, and tumor growth by topotecan in U251-HRE glioblastoma xenografts. Cancer Research 64, 6845-6848

104 Koh, M.Y. et al. (2008) Molecular mechanisms for the activity of PX-478, an antitumor inhibitor of the hypoxia-inducible factor-1alpha. Molecular Cancer Therapeutics 7, 90-100

105 Macpherson, G.R. and Figg, W.D. (2004) Small molecule-mediated anti-cancer therapy via hypoxia-inducible factor-1 blockade. Cancer Biology and Therapy 3, 503-504

106 Welsh, S. et al. (2004) Antitumor activity and pharmacodynamic properties of PX-478, an inhibitor of hypoxia-inducible factor-1alpha. Molecular Cancer Therapeutics 3, 233-244

107 Manabe, H. et al. (2008) Inhibition of histone deacetylase down-regulates the expression of hypoxia-induced vascular endothelial growth factor by rheumatoid synovial fibroblasts. Inflammation Research 57, 4-10

108 Mie Lee, Y. et al. (2003) Inhibition of hypoxiainduced angiogenesis by FK228, a specific histone deacetylase inhibitor, via suppression of HIF-1alpha activity. Biochemical and Biophysical Research Communications 300, 241-246

109 Sasakawa, Y. et al. (2003) Effects of FK228, a novel histone deacetylase inhibitor, on tumor growth and expression of p21 and c-myc genes in vivo. Cancer Letters 195, 161-168

110 Sasakawa, Y. et al. (2003) Antitumor efficacy of FK228, a novel histone deacetylase inhibitor, depends on the effect on expression of angiogenesis factors. Biochemical Pharmacology $66,897-906$ 
111 Yang, Q.C. et al. (2006) Inhibition of hypoxiainduced angiogenesis by trichostatin A via suppression of HIF-1a activity in human osteosarcoma. Journal of Experimental and Clinical Cancer Research 25, 593-599

112 Alqawi, O., Moghaddas, M. and Singh, G. (2006) Effects of geldanamycin on HIF-1alpha mediated angiogenesis and invasion in prostate cancer cells. Prostate Cancer and Prostatic Diseases 9, 126-135

113 Isaacs, J.S. et al. (2002) Hsp90 regulates a von Hippel Lindau-independent hypoxia-inducible factor-1 alpha-degradative pathway. Journal of Biological Chemistry 277, 29936-29944

114 Kim, W.Y. et al. (2009) Targeting heat shock protein 90 overrides the resistance of lung cancer cells by blocking radiation-induced stabilization of hypoxia-inducible factor-1alpha. Cancer Research 69, 1624-1632

115 Lang, S.A. et al. (2007) Targeting heat shock protein 90 in pancreatic cancer impairs insulin-like growth factor-I receptor signaling, disrupts an interleukin6/signal-transducer and activator of transcription 3/hypoxia-inducible factor-1alpha autocrine loop, and reduces orthotopic tumor growth. Clinical Cancer Research 13, 6459-6468

116 Liu, Y.V. et al. (2007) RACK1 competes with HSP90 for binding to HIF-1alpha and is required for $\mathrm{O}(2)$-independent and HSP90 inhibitor-induced degradation of HIF-1alpha. Molecular Cell 25, 207-217

117 Zhang, H. et al. (2008) Digoxin and other cardiac glycosides inhibit HIF-1alpha synthesis and block tumor growth. Proceedings of the National Academy of Sciences of the United States of America 105, 19579-19586

118 Gordan, J.D. et al. (2007) HIF-2alpha promotes hypoxic cell proliferation by enhancing c-myc transcriptional activity. Cancer Cell 11, 335-347

119 Gordan, J.D. et al. (2008) HIF-alpha effects on c-Myc distinguish two subtypes of sporadic VHL-deficient clear cell renal carcinoma. Cancer Cell 14, 435-446

120 Chen, H.H. et al. (2007) Hypoxia-inducible factor1alpha correlates with MET and metastasis in node-negative breast cancer. Breast Cancer Research and Treatment 103, 167-175

121 Hara, S. et al. (2006) Hypoxia enhances c-Met/HGF receptor expression and signaling by activating HIF-1alpha in human salivary gland cancer cells. Oral Oncology 42, 593-598

122 Hayashi, M. et al. (2005) Up-regulation of c-met protooncogene product expression through hypoxia-inducible factor-1alpha is involved in trophoblast invasion under low-oxygen tension. Endocrinology 146, 4682-4689

123 Lim, J.H. et al. (2004) Ras-dependent induction of HIF-1alpha785 via the Raf/MEK/ERK pathway: a novel mechanism of Ras-mediated tumor promotion. Oncogene 23, 9427-9431

124 Giles, R.H. et al. (2006) Interplay between VHL/HIF1alpha and Wnt/beta-catenin pathways during colorectal tumorigenesis. Oncogene 25, 3065-3070

125 Jiang, Y. et al. (2007) Hypoxia induces transforming growth factor-beta1 gene expression in the pulmonary artery of rats via hypoxia-inducible factor-1alpha. Acta Biochimica et Biophysica Sinica (Shanghai) 39, 73-80

126 Kaidi, A., Williams, A.C. and Paraskeva, C. (2007) Interaction between beta-catenin and HIF-1 promotes cellular adaptation to hypoxia. Nature Cell Biology 9, 210-217

127 Covello, K.L., Simon, M.C. and Keith, B. (2005) Targeted replacement of hypoxia-inducible factor1alpha by a hypoxia-inducible factor-2alpha knock-in allele promotes tumor growth. Cancer Research 65, 2277-2286

$128 \mathrm{Hu}$, C.J. et al. (2006) Differential regulation of the transcriptional activities of hypoxia-inducible factor 1 alpha (HIF-1alpha) and HIF-2alpha in stem cells. Molecular and Cellular Biology 26, 3514-3526

129 Sowter, H.M. et al. (2003) Predominant role of hypoxia-inducible transcription factor (Hif)1alpha versus Hif-2alpha in regulation of the transcriptional response to hypoxia. Cancer Research 63, 6130-6134

130 Rankin, E.B. et al. (2008) Hypoxia-inducible factor2 regulates vascular tumorigenesis in mice. Oncogene 27, 5354-5358

131 Silva, P. et al. (2008) Prognostic significance of tumor hypoxia inducible factor-1alpha expression for outcome after radiotherapy in oropharyngeal cancer. International Journal of Radiation Oncology Biology Physics 72, 1551-1559

132 Tzao, C. et al. (2008) Expression of hypoxiainducible factor (HIF)-1alpha and vascular endothelial growth factor (VEGF)-D as outcome predictors in resected esophageal squamous cell carcinoma. Disease Markers 25, 141-148

133 Uehara, M. et al. (2009) Hypoxia-inducible factor 1 alpha in oral squamous cell carcinoma and its relation to prognosis. Oral Oncology 45, 241-246

134 Trastour, C. et al. (2007) HIF-1alpha and CA IX staining in invasive breast carcinomas: prognosis 
and treatment outcome. International Journal of Cancer 120, 1451-1458

135 Motzer, R.J. et al. (2007) Sunitinib versus interferon alfa in metastatic renal-cell carcinoma. New England Journal of Medicine 356, 115-124

136 Motzer, R.J. et al. (2006) Activity of SU11248, a multitargeted inhibitor of vascular endothelial growth factor receptor and platelet-derived growth factor receptor, in patients with metastatic renal cell carcinoma. Journal of Clinical Oncology 24, 16-24

137 Ratain, M.J. et al. (2006) Phase II placebo-controlled randomized discontinuation trial of sorafenib in patients with metastatic renal cell carcinoma. Journal of Clinical Oncology 24, 2505-2512

138 O'Brien, M.F., Russo, P. and Motzer, R.J. (2008) Sunitinib therapy in renal cell carcinoma. BJU International 101, 1339-1342

139 Turcotte, S. et al. (2008) A molecule targeting VHL-deficient renal cell carcinoma that induces autophagy. Cancer Cell 14, 90-102

140 Bommi-Reddy, A. et al. (2008) Kinase requirements in human cells: III. Altered kinase requirements in $\mathrm{VHL}-/$ - cancer cells detected in a pilot synthetic lethal screen. Proceedings of the National Academy of Sciences of the United States of America 105, 16484-16489

141 Doll, C.M. et al. (2003) Estimating hypoxic status in human tumors: a simulation using Eppendorf oxygen probe data in cervical cancer patients. International Journal of Radiation Oncology Biology Physics 55, 1239-1246

142 Movsas, B. et al. (2001) Hypoxia in human prostate carcinoma: an Eppendorf PO2 study. American Journal of Clinical Oncology 24, 458-461

143 Kaanders, J.H. et al. (2002) Pimonidazole binding and tumor vascularity predict for treatment outcome in head and neck cancer. Cancer Research 62, 7066-7074

144 Evans, S.M. et al. (2000) Detection of hypoxia in human squamous cell carcinoma by EF5 binding. Cancer Research 60, 2018-2024

145 Raleigh, J.A. et al. (1998) Hypoxia and vascular endothelial growth factor expression in human squamous cell carcinomas using pimonidazole as a hypoxia marker. Cancer Research 58, 3765-3768

146 Brahme, A. (2003) Biologically optimized 3-dimensional in vivo predictive assay-based radiation therapy using positron emission tomography-computerized tomography imaging. Acta Oncologica 42, 123-136
147 Padhani, A.R. et al. (2007) Imaging oxygenation of human tumours. European Radiology 17, 861-872

148 Rajendran, J.G. and Krohn, K.A. (2005) Imaging hypoxia and angiogenesis in tumors. Radiologic Clinics of North America 43, 169-187

149 Gagel, B. et al. (2006) [18F] fluoromisonidazole and [18F] fluorodeoxyglucose positron emission tomography in response evaluation after chemo-/radiotherapy of non-small-cell lung cancer: a feasibility study. BMC Cancer 6, 51

150 Rajendran, J.G. et al. (2006) Tumor hypoxia imaging with [F-18] fluoromisonidazole positron emission tomography in head and neck cancer. Clinical Cancer Research 12, 5435-5441

151 Thorwarth, D. et al. (2006) Combined uptake of [18F]FDG and [18F]FMISO correlates with radiation therapy outcome in head-and-neck cancer patients. Radiotherapy and Oncology 80, 151-156

152 Troost, E.G. et al. (2008) Correlation of [18F]FMISO autoradiography and pimonodazole immunohistochemistry in human head and neck carcinoma xenografts. European Journal of Nuclear Medicine and Molecular Imaging 35, 1803-1811

153 Hendriksen, E.M. et al. (2009) Angiogenesis, hypoxia and VEGF expression during tumour growth in a human xenograft tumour model. Microvascular Research 77, 96-103

154 Kong, D. et al. (2005) Echinomycin, a smallmolecule inhibitor of hypoxia-inducible factor-1 DNA-binding activity. Cancer Research 65, 9047-9055

155 Jones, D.T. and Harris, A.L. (2006) Identification of novel small-molecule inhibitors of hypoxiainducible factor-1 transactivation and DNA binding. Molecular Cancer Therapeutics 5, 2193-2202

156 Lin, X. et al. (2008) A chemical genomics screen highlights the essential role of mitochondria in HIF-1 regulation. Proceedings of the National Academy of Sciences of the United States of America 105, 174-179

157 Lee, K. et al. (2009) Anthracycline chemotherapy inhibits HIF-1 transcriptional activity and tumorinduced mobilization of circulating angiogenic cells. Proceedings of the National Academy of Sciences of the United States of America 106, 2353-2358

158 Greenberger, L.M. et al. (2008) A RNA antagonist of hypoxia-inducible factor-1alpha, EZN-2968, 
inhibits tumor cell growth. Molecular Cancer Therapeutics 7, 3598-3608

159 Dikmen, Z.G. et al. (2008) In vivo and in vitro effects of a HIF-1alpha inhibitor, RX-0047. Journal of Cellular Biochemistry 104, 985-994

160 McEvoy, L.M. et al. (2005) HIF oligonucleotide decoy molecules. US Patent 056795

161 Buchler, P. et al. (2004) Antiangiogenic activity of genistein in pancreatic carcinoma cells is mediated by the inhibition of hypoxia-inducible factor-1 and the down-regulation of VEGF gene expression. Cancer 100, 201-210

162 Sandau, K.B., Faus, H.G. and Brune, B. (2000) Induction of hypoxia-inducible-factor 1 by nitric oxide is mediated via the PI 3K pathway. Biochemical and Biophysical Research Communications 278, 263-267

163 Sandau, K.B. et al. (2001) Regulation of the hypoxia-inducible factor 1 alpha by the inflammatory mediators nitric oxide and tumor necrosis factor-alpha in contrast to desferroxamine and phenylarsine oxide. Journal of Biological Chemistry 276, 39805-39811

164 Wang, B. et al. (2005) Genistein inhibited hypoxiainducible factor-1alpha expression induced by hypoxia and cobalt chloride in human retinal pigment epithelium cells. Methods and Findings in Experimental and Clinical Pharmacology 27, 179-184

165 Calvani, M. et al. (2008) Differential involvement of vascular endothelial growth factor in the survival of hypoxic colon cancer cells. Cancer Research 68, 285-291

$166 \mathrm{Lu}$, Y. et al. (2007) Responses of cancer cells with wild-type or tyrosine kinase domain-mutated epidermal growth factor receptor (EGFR) to EGFRtargeted therapy are linked to downregulation of hypoxia-inducible factor-1alpha. Molecular Cancer 6, 63

167 Luwor, R.B. et al. (2005) The antiepidermal growth factor receptor monoclonal antibody cetuximab/ C225 reduces hypoxia-inducible factor- 1 alpha, leading to transcriptional inhibition of vascular endothelial growth factor expression. Oncogene 24, 4433-4441

168 Pore, N. et al. (2006) EGFR tyrosine kinase inhibitors decrease VEGF expression by both hypoxia-inducible factor (HIF)-1-independent and HIF-1-dependent mechanisms. Cancer Research 66, 3197-3204

169 Alam, H. et al. (2009) Role of the phosphatidylinositol-3-kinase and extracellular regulated kinase pathways in the induction of hypoxia-inducible factor (HIF)- 1 activity and the HIF-1 target vascular endothelial growth factor in ovarian granulosa cells in response to follicle-stimulating hormone. Endocrinology 150, 915-928

170 Sutton, K.M. et al. (2007) Selective inhibition of MEK1/2 reveals a differential requirement for ERK1/2 signalling in the regulation of HIF-1 in response to hypoxia and IGF-1. Oncogene 26, 3920-3929

171 Kumar, S.M. et al. (2007) Mutant V600E BRAF increases hypoxia inducible factor-1alpha expression in melanoma. Cancer Research 67, 3177-3184

172 Pore, N. et al. (2006) Nelfinavir down-regulates hypoxia-inducible factor 1alpha and VEGF expression and increases tumor oxygenation: implications for radiotherapy. Cancer Research 66, 9252-9259

173 Pore, N. et al. (2006) HIV protease inhibitors decrease VEGF/HIF-1alpha expression and angiogenesis in glioblastoma cells. Neoplasia 8, 889-895

174 Garcia-Maceira, P. and Mateo, J. (2009) Silibinin inhibits hypoxia-inducible factor-1alpha and $\mathrm{mTOR} / \mathrm{p} 70 \mathrm{S6K} / 4 \mathrm{E}-\mathrm{BP} 1$ signalling pathway in human cervical and hepatoma cancer cells: implications for anticancer therapy. Oncogene 28, 313-324

175 Stewart, G.D. et al. (2009) NO-sulindac inhibits the hypoxia response of PC-3 prostate cancer cells via the Akt signalling pathway. International Journal of Cancer 124, 223-232

176 Pencreach, E. et al. (2009) Marked activity of irinotecan and rapamycin combination toward colon cancer cells in vivo and in vitro is mediated through cooperative modulation of the mammalian target of rapamycin/hypoxiainducible factor-1alpha axis. Clinical Cancer Research 15, 1297-1307

177 Wang, W. et al. (2008) Antitumoral activity of rapamycin mediated through inhibition of HIF-1alpha and VEGF in hepatocellular carcinoma. Digestive Diseases and Sciences Dec 4; [Epub ahead of print]

178 Wan, X. et al. (2006) CCI-779 inhibits rhabdomyosarcoma xenograft growth by an antiangiogenic mechanism linked to the targeting of mTOR/Hif-1alpha/VEGF signaling. Neoplasia 8, 394-401

179 Cejka, D. et al. (2008) Everolimus (RAD001) and anti-angiogenic cyclophosphamide show long- 
term control of gastric cancer growth in vivo. Cancer Biology and Therapy 7, 1377-1385

180 Mabuchi, S. et al. (2007) RAD001 inhibits human ovarian cancer cell proliferation, enhances cisplatin-induced apoptosis, and prolongs survival in an ovarian cancer model. Clinical Cancer Research 13, 4261-4270

181 Fang, J. et al. (2007) Apigenin inhibits tumor angiogenesis through decreasing HIF-1alpha and VEGF expression. Carcinogenesis 28, 858-864

182 Liu, L.Z. et al. (2005) Apigenin inhibits expression of vascular endothelial growth factor and angiogenesis in human lung cancer cells: implication of chemoprevention of lung cancer. Molecular Pharmacology 68, 635-643

183 Mirzoeva, S. et al. (2008) Inhibition of HIF-1 alpha and VEGF expression by the chemopreventive bioflavonoid apigenin is accompanied by Akt inhibition in human prostate carcinoma PC3-M cells. Molecular Carcinogenesis 47, 686-700

184 Osada, M., Imaoka, S. and Funae, Y. (2004) Apigenin suppresses the expression of VEGF, an important factor for angiogenesis, in endothelial cells via degradation of HIF-1alpha protein. FEBS Letters 575, 59-63

$185 \mathrm{Kim}, \mathrm{H} . \mathrm{L}$. et al. (2006) A domain responsible for HIF-1alpha degradation by YC-1, a novel anticancer agent. International Journal of Oncology 29, 255-260

186 Lau, C.K. et al. (2006) Suppression of hypoxia inducible factor-1alpha (HIF-1alpha) by YC-1 is dependent on murine double minute 2 (Mdm2). Biochemical and Biophysical Research Communications 348, 1443-1448

187 Sun, H.L. et al. (2007) YC-1 inhibits HIF-1 expression in prostate cancer cells: contribution of Akt/NF-kappaB signaling to HIF-1alpha accumulation during hypoxia. Oncogene 26, 3941-3951

188 Zhao, Q. et al. (2007) Effects of YC-1 on hypoxiainducible factor 1-driven transcription activity, cell proliferative vitality, and apoptosis in hypoxic human pancreatic cancer cells. Pancreas 34, $242-247$

189 Huang, S.P. et al. (2005) Cyclooxygenase-2 increases hypoxia-inducible factor- 1 and vascular endothelial growth factor to promote angiogenesis in gastric carcinoma. Journal of Biomedical Science 12, 229-241

190 Jones, M.K. et al. (2002) von Hippel Lindau tumor suppressor and HIF-1alpha: new targets of NSAIDs inhibition of hypoxia-induced angiogenesis. FASEB Journal 16, 264-266
191 Zhong, H., Willard, M. and Simons, J. (2004) NS398 reduces hypoxia-inducible factor (HIF)-1alpha and HIF-1 activity: multiple-level effects involving cyclooxygenase-2 dependent and independent mechanisms. International Journal of Cancer 112, 585-595

192 Palayoor, S.T., Tofilon, P.J. and Coleman, C.N. (2003) Ibuprofen-mediated reduction of hypoxiainducible factors HIF-1alpha and HIF-2alpha in prostate cancer cells. Clinical Cancer Research 9, 3150-3157

193 Fath, D.M. et al. (2006) Histone deacetylase inhibitors repress the transactivation potential of hypoxia-inducible factors independently of direct acetylation of HIF-alpha. Journal of Biological Chemistry 281, 13612-13619

194 Qian, D.Z. et al. (2004) The histone deacetylase inhibitor NVP-LAQ824 inhibits angiogenesis and has a greater antitumor effect in combination with the vascular endothelial growth factor receptor tyrosine kinase inhibitor PTK787/ZK222584. Cancer Research 64, 6626-6634

195 Thomas, S.L. et al. (2008) EF24, a novel curcumin analog, disrupts the microtubule cytoskeleton and inhibits HIF-1. Cell Cycle 7, 2409-2417

196 Mabjeesh, N.J. et al. (2003) 2ME2 inhibits tumor growth and angiogenesis by disrupting microtubules and dysregulating HIF. Cancer Cell 3, 363-375

197 Mooberry, S.L. (2003) Mechanism of action of 2-methoxyestradiol: new developments. Drug Resistance Updates 6, 355-361

198 Ricker, J.L. et al. (2004) 2-methoxyestradiol inhibits hypoxia-inducible factor 1alpha tumor growth, and angiogenesis and augments paclitaxel efficacy in head and neck squamous cell carcinoma. Clinical Cancer Research 10, 8665-8673

199 LaVallee, T.M. et al. (2008) Significant antitumor activity in vivo following treatment with the microtubule agent ENMD-1198. Molecular Cancer Therapeutics 7, 1472-1482

200 Moser, C. et al. (2008) ENMD-1198, a novel tubulinbinding agent reduces HIF-1alpha and STAT3 activity in human hepatocellular carcinoma(HCC) cells, and inhibits growth and vascularization in vivo. BMC Cancer 8, 206

201 Kim, H.S. et al. (2008) Paclitaxel induces vascular endothelial growth factor expression through reactive oxygen species production. Pharmacology $81,317-324$

202 Vlaminck, B. et al. (2007) Dual effect of echinomycin on hypoxia-inducible factor-1 
activity under normoxic and hypoxic conditions. FEBS Journal 274, 5533-5542

203 Olenyuk, B.Z. et al. (2004) Inhibition of vascular endothelial growth factor with a sequence-specific hypoxia response element antagonist. Proceedings of the National Academy of Sciences of the United States of America 101, 16768-16773

204 Duyndam, M.C. et al. (2007) Cisplatin and doxorubicin repress Vascular Endothelial Growth Factor expression and differentially down-regulate Hypoxia-inducible Factor I activity in human ovarian cancer cells. Biochemical Pharmacology 74, 191-201

205 LaRusch, G.A. et al. (2007) Nutlin3 blocks vascular endothelial growth factor induction by preventing the interaction between hypoxia inducible factor 1alpha and Hdm2. Cancer Research 67, 450-454

206 Jordan, B.F. et al. (2005) Metabolite changes in HT-29 xenograft tumors following HIF-1alpha inhibition with PX-478 as studied by MR spectroscopy in vivo and ex vivo. NMR in Biomedicine 18, 430-439

207 Jordan, B.F. et al. (2005) Dynamic contrastenhanced and diffusion MRI show rapid and dramatic changes in tumor microenvironment in response to inhibition of HIF-1alpha using PX-478. Neoplasia 7, 475-485

208 Palayoor, S.T. et al. (2008) PX-478, an inhibitor of hypoxia-inducible factor-1alpha, enhances radiosensitivity of prostate carcinoma cells. International Journal of Cancer 123, 2430-2437

209 Werno, C., Zhou, J. and Brune, B. (2008) A23187, ionomycin and thapsigargin upregulate mRNA of HIF-1alpha via endoplasmic reticulum stress rather than a rise in intracellular calcium. Journal of Cellular Physiology 215, 708-714

210 Zhu, K. et al. (2009) Control of HIF-1alpha expression by eIF2 alpha phosphorylationmediated translational repression. Cancer Research 69, 1836-1843

211 Rapisarda, A. and Melillo, G. (2007) UVC inhibits HIF-1alpha protein translation by a DNA damageand topoisomerase I-independent pathway. Oncogene 26, 6875-6884

212 Puppo, M. et al. (2008) Topotecan inhibits vascular endothelial growth factor production and angiogenic activity induced by hypoxia in human neuroblastoma by targeting hypoxia-inducible factor-1alpha and -2alpha. Molecular Cancer Therapeutics 7, 1974-1984
213 Creighton-Gutteridge, M. et al. (2007) Cell typespecific, topoisomerase II-dependent inhibition of hypoxia-inducible factor-1alpha protein accumulation by NSC 644221. Clinical Cancer Research 13, 1010-1018

214 Kamiyama, H. et al. (2005) Anti-angiogenic effects of SN38 (active metabolite of irinotecan): inhibition of hypoxia-inducible factor 1 alpha (HIF-1alpha)/ vascular endothelial growth factor (VEGF) expression of glioma and growth of endothelial cells. Journal of Cancer Research and Clinical Oncology 131, 205-213

215 Maeda, M. et al. (2006) Inhibition of angiogenesis and HIF-1alpha activity by antimycin A1. Biological and Pharmaceutical Bulletin 29, 1344-1348

216 Hagen, T. et al. (2003) Redistribution of intracellular oxygen in hypoxia by nitric oxide: effect on HIF1alpha. Science 302, 1975-1978

217 Xia, C. et al. (2007) Reactive oxygen species regulate angiogenesis and tumor growth through vascular endothelial growth factor. Cancer Research 67, 10823-10830

218 Welsh, S.J. et al. (2003) The thioredoxin redox inhibitors 1-methylpropyl 2-imidazolyl disulfide and pleurotin inhibit hypoxia-induced factor 1alpha and vascular endothelial growth factor formation. Molecular Cancer Therapeutics 2, 235-243

219 Groot, A.J. et al. (2008) Conditional inactivation of HIF-1 using intrabodies. Cellular Oncology 30, 397-409

220 Yasui, H. et al. (2008) Inhibition of HIF-1alpha by the anticancer drug TAS106 enhances X-rayinduced apoptosis in vitro and in vivo. British Journal of Cancer 99, 1442-1452

221 Zeng, L. et al. (2008) TS-1 enhances the effect of radiotherapy by suppressing radiation-induced hypoxia-inducible factor- 1 activation and inducing endothelial cell apoptosis. Cancer Science 99, 2327-2335

$222 \mathrm{Wu}, \mathrm{H}$. et al. (2008) Resveratrol inhibits hypoxiainduced metastasis potential enhancement by restricting hypoxia-induced factor- 1 alpha expression in colon carcinoma cells. Biomedicine and Pharmacotherapy 62, 613-621

223 Newcomb, E.W. et al. (2005) Flavopiridol downregulates hypoxia-mediated hypoxiainducible factor-1alpha expression in human glioma cells by a proteasome-independent pathway: implications for in vivo therapy. NeuroOncology 7, 225-235 


\section{Further reading, resources and contacts}

Davis, D.W., Herbst, R.S. and Abbruzzese, J.L., eds (2008) Antiangiogenic Cancer Therapy, CRC Press

One of the most widely pursued therapeutic strategies in cancer therapy has been to target the angiogenic process, which is regulated by the hypoxia/HIF pathway in tumour progression. This book comprehensively reviews the progress made in antiangiogenic cancer therapies in recent years.

Online sources of general information on cancer research:

http://www.cancer.gov (US National Cancer Institute)

http://www.cancer.org.uk (Cancer Research UK)

http://www.oncolink.org (web-based cancer resource, University of Pennsylvania, USA)

http://www.icr.ac.uk/ (The Institute of Cancer Research, UK)

http://www.ucl.ac.uk/cancer/ (UCL Cancer Institute, UK)

\section{Features associated with this article}

\section{Figures}

Figure 1. Increased hypoxia is detected at increasing tumour size.

Figure 2. Schematic representation of HIF-1 $\alpha$ and its four functional domains.

Figure 3. HIF-1 $\alpha$ expression is deregulated in cancer.

Figure 4. Strategies to target the HIF-1 pathway in cancer.

\section{Tables}

Table 1. Strategies to identify inhibitors of HIF-1 $\alpha$ and the HIF pathway.

Table 2. Anticancer agents that decrease HIF-1 $\alpha$ and target the HIF-1 pathway.

\section{Citation details for this article}

Evon Poon, Adrian L. Harris and Margaret Ashcroft (2009) Targeting the hypoxia-inducible factor (HIF) pathway in cancer. Expert Rev. Mol. Med. Vol. 11, e26, August 2009, doi:10.1017/S1462399409001173 